\title{
Laboratory tests and analysis of CIPP epoxy resin internal liners used in pipelines - part II: comparative analysis with the use of the FEM and engineering algorithms
}

https://doi.org/10.2478/sgem-2021-0007

received November 15, 2020; accepted March 16, 2021.

\begin{abstract}
In the case of underground network infrastructure it can be seen that objects functioning in the second technical condition, according to DWA-ATV 143-2, and subjected to rehabilitation with the use of close-fit trenchless technologies are capable of withstanding external loads. The main external load that is taken into account in engineering calculations in the case of conduits in the second technical condition is external groundwater pressure.
\end{abstract}

In order to compare design parameters obtained with the use of various calculation methods, a comparative analysis was conducted in order to determine the values of critical pressure. The calculations were carried out using popular engineering algorithms.

In addition, analyses using the Finite Element Method and Abaqus software as a computational tool were carried out for the purpose of verifying laboratory tests. This paper aims to broaden knowledge concerning the possibility of performing control numerical analyses for close-fit liners installed in pipelines that are in the second technical condition according to DWA-ATV 143-2.

The analyses were carried out on ten $3 \mathrm{D}$ models. The models were parameterized in order to reflect the CIPP samples in the most accurate way. The computational models were built based on assumptions, which are commonly used in this type of scientific analysis, regarding material parameters and their interactions.

The direct value of the performed engineering calculations and numerical analyses is the extension of knowledge in the field of strength parameters that are obtained by various material groups of close-fit liners. Comparative analysis of the results of laboratory tests and

\footnotetext{
*Corresponding author: Tomasz Abel, Wroctaw University of Science and Technology, Wybrzeże Wyspiańskiego 27, 50-370 Wrocław,

Poland, E-mail: tomasz.abel@pwr.edu.pl
}

numerical analyses, and the conclusions that result from them, constitute the basis for the optimization of the design process and the individual approach to issues related to the use of liners that strengthen underground pipelines.

Keywords: no-dig technologies, laboratory tests, closefit lining, sewer rehabilitation

\section{Introduction}

Currently, several computational methods, which are included in guidelines and standards, are used worldwide in order to select the strength parameters of close-fit CIPP linings $[1,2]$. In the USA, it is the ASTM F1216 standard [3], and in Europe, the French RERAU guidelines [4], the English WRc SRM guidelines [5], and the German DWA 143-2 guidelines [6].

The listed standard and guidelines include the computational algorithms that are used in engineering practice during the process of designing renovating liners. Verification of the correctness of the renovation is carried out by performing the acceptance tests that are described in the first part of this paper [7]. To this end, it is also possible to use the finite element method, the assumptions of which are based, among others, on the fact that each quantity that is described by means of a continuous function is approximated by a discrete model [8]. Therefore, in order to broaden knowledge about the strength parameters of CIPP liners, and because of the need to optimise design solutions, CIPP liner samples were subjected to engineering calculations, numerical analyses, and laboratory tests as part of the research programme, which was shown in the first part of this article [7] where fragments of liners taken from conduits with diameters of $\varnothing 200, \varnothing 350$, and $\varnothing 500$, representative for non-man-entry sanitary sewage networks that occur 


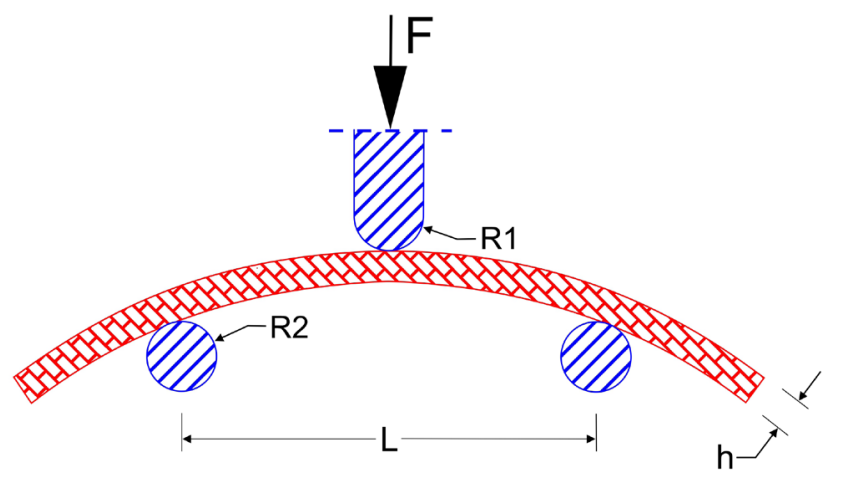

Figure 1: Three-point bending - test scheme.

in urban areas, were tested (the laboratory test stand is shown in Fig. 1).

The following laboratory tests are carried out:

- Bending tensile strength - This is a characteristic feature for liners and allows the permissible load value to be determined. The value of this strength is defined by the point of destruction of the sample that is subjected to an increasing load.

- Modulus of longitudinal elasticity - The test method also involves the three-point bending test, which is carried out on the basis of PN-EN ISO 178: 2019-06 [9] as a short-term test.

- Measuring the wall thickness of the liner - The fitted liner is measured using a precise calliper in six places.

- Waterproofness of the liner using GWT [10] method - Sealed pressure chamber is attached to the tested surface and then filled with boiled coloured water, which is subjected to forced pressure - for CIPP liners with a value of minimum 0.5 bar.

The engineering calculation performed confirmed that repair with the use of CIPP lining provides high safety reserves, which guarantees further safe operation of the network and eliminates the progression of factors that cause deterioration of the technical condition of the conduit.

The algorithms that are currently in use can be classified into two categories: the first includes methods derived from the Timoshenko formula [11], and the second group are methods based on the conditions described by Glock [12]. In the case of close-fit linings, the basic value that determines the safety of a composite structure (pipeliner) is the value of the permissible external critical pressure, which is caused by an appropriate group of external loads that may act on the structure. The formulas for determining the values of critical pressures according to the above two algorithms are shown in Table 1.
The values calculated according to Timoshenko's guidelines are important with regard to the assumption that the existing pipeline does not circumferentially support a liner. Glock's theory, on the other hand, assumes a rigid support of the liner in the area of the sidewall surface and the top of the existing pipeline. In both cases, these assumptions apply to ideal models that are not affected by the irregularities that often occur in crosssections. In reality, pipe-liner systems may be burdened with large inaccuracies resulting from the actual technical condition of the conduit. Therefore, it is necessary to take into account any imperfections that may exist in the crosssections of such systems. The schemes of Timoshenko's and Glock's models are shown in Figure $2[11,12]$.

Independent and appropriate consideration of all imperfections in the calculation algorithm is a very important aspect, as was indicated, among others, in paper [13]. This article presents an analysis of the problem of basic imperfections to which CIPP type lining is exposed, and their influence on the values of permissible critical loads, including, in particular, the values of critical pressure $\mathrm{p}_{\mathrm{cr}}$.

The analyses were performed for models with three different imperfections separately, as well as for models with all imperfections synergistically. Such a broad analysis of the problem enabled the changes in the size of the impact of the occurring irregularities on the value of critical loads that may affect the lining to be determined. The calculations, which were performed as part of the research, aimed to find the optimal way to determine the value of the critical pressure. The main parameter that was checked in the numerical calculations was the value of the critical pressure of the groundwater that is representative for conduits in the second technical condition [6], for which CIPP linings are dedicated.

The paper shows that a thorough analysis of the influence of imperfections on the load capacity of linings enables the values of the used different reduction factors to be optimised, and thus lining wall thickness to be a precisely selected. Each calculation algorithm uses different safety factors as shown in the chapter 2 . The necessity to conduct further analyses of the algorithms that are currently used in the design process was confirmed. This, in turn, requires tests of CIPP linings to be conducted. At the same time, it was also indicated that an individual approach to the design process with regard to the technical condition of a given pipeline is necessary.

The research of scientists from around the world confirms the need to gain knowledge concerning the strength parameters of close-fit repair linings. One of the most interesting studies is paper [14], the authors of 
Timoshenko's model

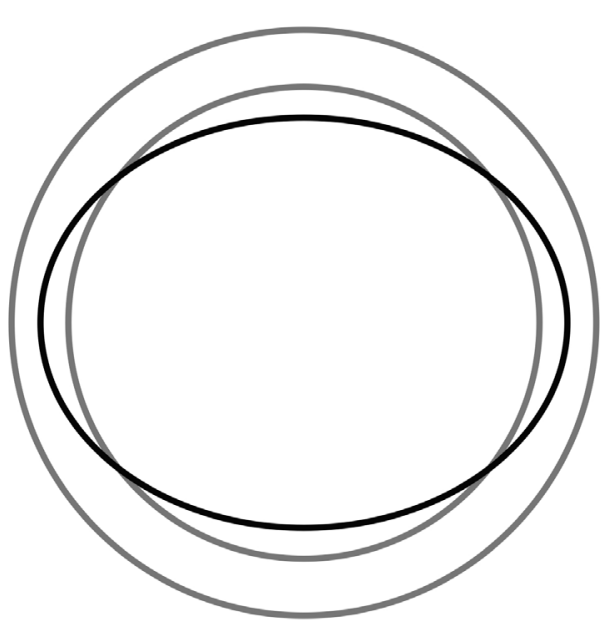

Figure 2: Computational models [11, 12].

Table 1: Critical pressures according to the Timoshenko`s and Glock`s algorithms.

Timoshenko`s formula

$p_{c r}=\frac{3 * E * I}{R^{3}}$

Glock`s formula

where:

$\mathrm{E}$ - Young's modulus of the liner's material [MPa]

I - moment of inertia of the system $\left[\mathrm{m}^{4}\right]$

$\mathrm{R}$ - nominal radius of the pipeline $[\mathrm{mm}]$

$\mathrm{h}$ - liner's wall thickness [mm]

D - liner's diameter [mm]

which conducted analyses and calculations using the finite element method (FEM) for damaged pipes that were reinforced with a close-fit polyethylene lining. The analyses were carried out for the interaction between the lining and the existing pipe, and also for the composite system (pipe-lining) located in the soil medium, which was externally loaded with uniformly distributed forces.

Analyses with the use of the FEM are very common in the field of underground network infrastructure. The author of this study, in 2015 [15], carried out analyses of concrete pipelines, which were previously tested as natural-scale laboratory models. The conducted numerical calculations resulted in the obtaining of a reliable discrete model that correctly describes the nature of the operation of a pipeline reinforced with CIPP lining supported on an elastic substrate, i.e. the soil medium.

Scientists around the world use the FEM as a tool to verify engineering calculations, as well as a control for

\section{Glock's model}

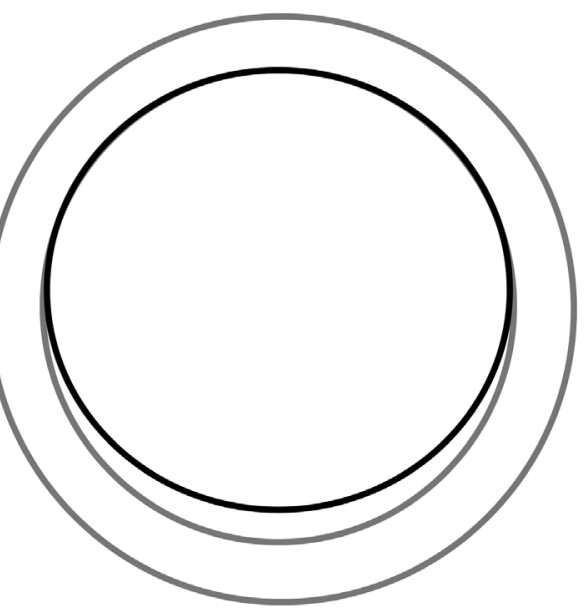

laboratory research. The use of the FEM enables models that guarantee the obtaining of reliable results of analyses to be constructed regardless of their complexity.

In 2004, a team consisting of W. Zhao and D. Hall [16] conducted a series of numerical analyses for CIPP linings with variable wall thicknesses. The two basic models were made of a liner in which the wall thickness varied in the longitudinal and transverse cross-sections. The analyses were carried out in order to obtain knowledge about the influence of the wall thickness of the lining on its strength parameters and on the operation of a structure. Moreover, the possible synergy effect of the occurrence of these changes was determined. The Abaqus system was used to perform the calculations.

Many researchers carry out numerical analyses of pipelines reinforced with CIPP linings that are treated as composite structures. Such an approach is fully justified in the case of using close-fit linings. In paper [17], the influence of the corrugations of a lining that was installed in a cast iron pipeline was analysed. These types of irregularities occur at the stage of execution and often cause problems in the further trouble-free operation of the pipeline. The conducted research was supported by numerical calculations made using the Adina program.

In turn, paper [18] presents the computational possibilities offered by the use of the FEM when analysing gas networks renovated with close-fit polyethylene liners. As part of the analyses, a review of various computational methods of repairing point leaks in gas pipes was performed, and the level of effectiveness of individual methods that can be extremely useful in engineering practice was indicated. 
Numerical analyses are commonly carried out for pressure networks, because it is this group of pipelines (representative for underground transport infrastructure) that operates in extremely difficult conditions, i.e. in addition to external mechanical loads, there is a significant internal load in the form of the medium's pressure. The subject of research involves material and strength parameters, as well as the modelling of all types of damage and irregularities that may occur in the structure of the existing pipeline and the lining installed in it. This includes corrosion, the related local defects in the material structure [19], and also the geometry of the liner's longitudinal cross-section [20].

Numerical analyses of pipeline damage are carried out by researchers from three main fields of science, i.e. civil engineering, mechanics, and environmental protection. As shown by the latest publications [21], issues concerning damaged pipelines are constantly considered in order to obtain knowledge about changes in the material's structure and their impact on the safety of use and on the structure's load-bearing capacity.

The use of the FEM enabled deformations that are locally occurring (in the places of the highest stresses) in the liner's material and that are caused by geometric changes in the cross-section of the existing pipeline to be indicated. It was once again confirmed that in order to ensure many years of safe use of a conduit reinforced with CIPP lining, it is necessary to precisely take into account any irregularities in the conduit at the design stage.

The issue related to imperfections was also extensively analysed in [22]. The algorithm developed by Glock was analysed with regard to two cases: a scheme with one deformation and a scheme with two symmetrical deformations - which is a common phenomenon in the case of symmetrically loaded duct structures. Other imperfections that may occur, such as deviations of the basic parameters that are used in the Glock formula, were also considered. As a result, knowledge concerning the size of the impact of changes in the values of individual imperfections on the value of permissible critical pressure $\mathrm{p}_{\mathrm{cr}}$ was obtained.

\section{Algorithms used in engineering practice}

\subsection{The ASTM F 1216 formula [3]}

The ASTM F 1216 algorithm, based on Timoshenko's assumptions, is a computational scheme used in engineering practice in the USA. One of the characteristic parameters that determine the value of the critical pressure causing deformation of the liner is safety factor K. In the case of the ASTM algorithm for CIPP liners, the value of safety factor $\mathrm{K}$ is equal to 7 (this value was obtained as a result of laboratory tests). The permissible value of the critical pressure is given by the following formula:

$$
\frac{P_{c r}}{N}=a d m \cdot p=\frac{2 K \cdot E_{L}}{\left(1-v^{2}\right)} \cdot \frac{1}{(S D R-1)} \cdot \frac{C}{N}
$$

where: $\mathrm{N}$ - safety factor (assumed value of 2) [-], K coefficient taking into account the lining casing, which is the existing pipeline (an assumed value of 7 for CIPP liners) [-], $\mathrm{E}_{\mathrm{L}}$ - long-term modulus of elasticity of the liner $[\mathrm{MPa}], v$ - Poisson's ratio [-], C - reduction factor resulting from pipeline ovalisation [-], SDR - ratio of the nominal outer diameter to the nominal pipe wall thickness [-].

The reduction factor is calculated from formula:

$$
C=\left[\frac{1-q}{\left(1+q^{2}\right)}\right]^{3}
$$

while the ovalisation of $q$ is expressed as the relation:

$$
q(\%)=100 \cdot \frac{D_{h}-D_{v}}{D_{h}+D_{v}}
$$

where: $D_{h}$ - value of the horizontal diameter $[\mathrm{mm}], \mathrm{D}_{\mathrm{v}}-$ value of the vertical diameter [mm].

\subsection{The Thépot formula (RERAU National Project, France and AGHTM RRR) $[1,4,23]$}

In this algorithm, Thépot used reduction factors, which take into account the influence of two types of deformation. He determined the formula for the critical pressure as follows:

$$
p_{c r}=\Gamma_{p, h} \cdot \Gamma_{p, g} \cdot \beta_{k} \cdot \frac{E I_{L}}{R^{3}}
$$

$$
\beta_{k}=2.02 \cdot\left(k \cdot \frac{E A_{L}}{P} \cdot \frac{R^{3}}{E I_{L}}\right)^{0.4}
$$


where: $\mathrm{E}$ - Young's modulus [MPa], $\mathrm{A}_{\mathrm{L}}$ - cross-sectional area of the lining $\left[\mathrm{mm}^{2}\right], \mathrm{I}_{\mathrm{L}}-$ moment of inertia of the liner $\left[\mathrm{mm}^{4}\right]$, $\mathrm{R}$ - nominal radius [mm], $\mathrm{P}$ - liner's circumference $[\mathrm{mm}]$.

In the case of a uniform material $\left(E I / E A=h^{2} / 12\right)$ and a circular shape $(\mathrm{P}=2 \pi \mathrm{R}), \beta_{\mathrm{k}}$ can be expressed using the following relationship:

$$
\beta_{k}=2.62 \cdot k^{0,4} \cdot\left(\frac{R}{h}\right)^{0.8}
$$

where: $\mathrm{k}=1$ for one deformation, $\mathrm{k}=2$ for two deformations, $\mathrm{R}$ - nominal radius [mm], $\mathrm{h}$ - liner wall thickness [mm].

The values of the reduction factors are calculated as follows:

$$
\begin{aligned}
& \Gamma_{p, g}=\frac{1}{1+0,41 \cdot \delta_{g}-0,006 \cdot \delta_{g}^{2}} \\
& \Gamma_{p, h}=\frac{1}{1+0,41 \cdot \delta_{h}-0,006 \cdot \delta_{h}^{2}}
\end{aligned}
$$

where $\delta_{\mathrm{g}}$ and $\delta_{\mathrm{h}}$ are the values of the reduced annular space and the reduced ovalisation, respectively. These values are determined using the following formulas (in the model with two deformations):

$$
\begin{gathered}
\delta_{g}=2.94 \cdot \frac{g}{h} \cdot\left(\frac{R}{h}\right)^{0.2} \\
\delta_{h}=0,515 \cdot t \cdot\left(\frac{R}{h}\right)^{0.4}
\end{gathered}
$$

where: $\mathrm{g}$ - width of the annular gap [mm], $\mathrm{t}$ - vertical diameter after ovalisation [mm].

In addition, a global reduction factor, which is a combination of values of the reduced annular space and the reduced ovalisation, can be used:

$$
\Gamma_{p, g \cdot h}=\frac{1-4 \cdot \delta_{h}+4,9 \cdot \delta_{h}^{2}}{1+0,4 \cdot \delta_{g}-0,6 \cdot \delta_{g} \cdot \delta_{h}}
$$

\subsection{A method of dimensioning according to the WRc Sewerage Rehabilitation Manual 2001 [5]}

A dimensioning method according to WRc was developed on the basis of laboratory tests of samples of close-fit linings. The scope of the tests, as is the case in acceptance tests, included the determination of the material's elasticity modulus, ring stiffness, and bending strength.

The critical load $\mathrm{P}_{\mathrm{cr}}$ is given by the following formula:

$$
P_{c r}=Y_{2} \cdot \frac{E I}{N l^{3}}
$$

where: $Y_{2}-$ a coefficient, which is dependent on ratio $\mathrm{h} / \mathrm{l}$ [-], E - long-term Young's modulus [MPa], N - safety factor equal to 2,1 - horizontal width of the conduit (across its cross-section), which includes deformation [mm], I moment of inertia (liner wall).

\subsection{The DWA 143-2 algorithm [6]}

InEurope, the mostcommonly used guidelinesbydesigners are DWA guidelines [6]. The calculations according to this algorithm are based on the conducted investigations of a conduit's condition and its classification to one of four technical conditions. The DWA algorithm is a formula that takes into account three types of deformations (see [6, 10]). The value of the critical pressure is described using the following formula:

$$
p_{c r}=\kappa_{v} \cdot \kappa_{G R, v} \cdot \kappa_{S} \cdot \alpha_{D} \cdot s_{L}
$$

where $s_{L}-$ ring stiffness $\left[\mathrm{N} / \mathrm{mm}^{2}\right]$, and $\alpha_{\mathrm{D}}$ is a constant that is calculated according to formula:

$$
\alpha_{D}=2.62 \cdot\left(\frac{r_{L}}{s_{L}}\right)^{0.8}
$$

The ring stiffness is expressed as relationship:

$$
S_{L}=\frac{(E I)_{L}}{r_{L}^{3}}
$$

where: E - Young's modulus [MPa], I - moment of inertia of the liner $\left[\mathrm{m}^{4}\right], \mathrm{r}_{\mathrm{L}}-$ nominal radius of the liner $[\mathrm{mm}]$, $\kappa_{n}$ - reduction factor that depends on the value of local deformation $\mathrm{w}_{\mathrm{n}}, \mathrm{\kappa}_{\mathrm{GR}, \mathrm{n}}$ - reduction factor that depends on the value of local deformation $\mathrm{w}_{\mathrm{GR}, \mathrm{n}}, \kappa_{\mathrm{s}}$ - reduction factor that depends on the value of local deformation $\mathrm{w}_{\mathrm{s}}, \mathrm{w}_{\mathrm{n}}$ according to Figure 3, $\mathrm{w}_{\mathrm{GR}, \mathrm{n}}-$ according to Figure $3, \mathrm{w}_{\mathrm{s}}-$ according to Figure 3. 

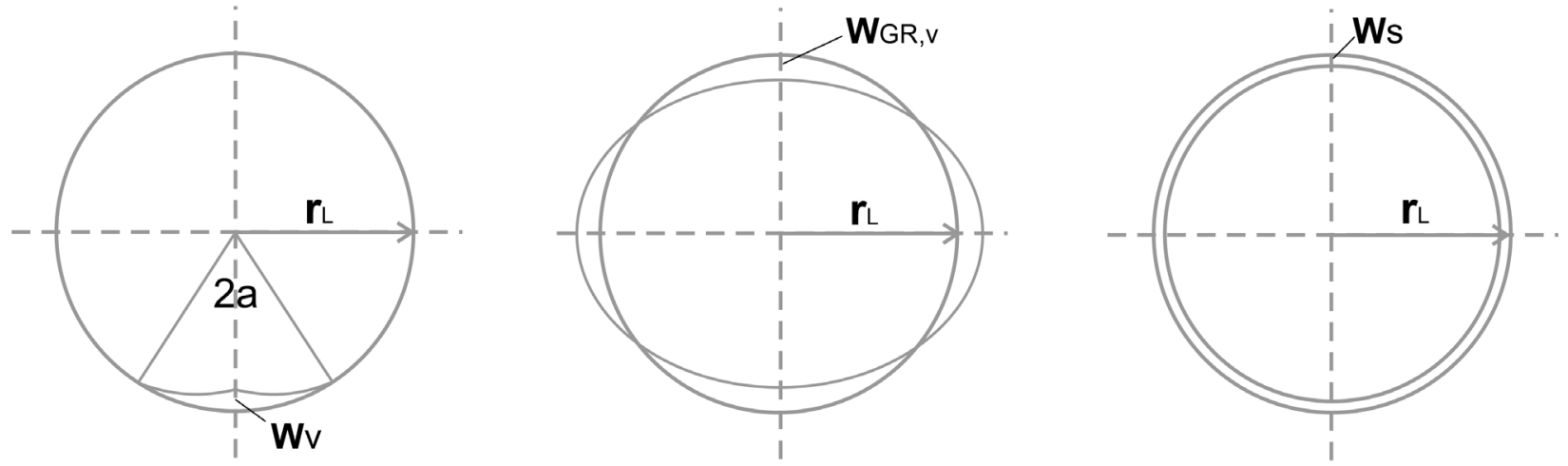

Figure 3: Imperfections of an existing conduit and liner: a) local deformation $w_{v}, b$ ) ovalisation $\left.w_{G R, v}, c\right)$ annular gap $w_{s}[6]$.

\subsection{Comparative analysis of methods}

Timoshenko's and Glock's formulas in the case of CIPP linings inside a conduit include geometric parameters and material properties when determining the critical pressure. The other algorithms based on the assumptions of Timoshenko or Glock introduce variables that characterise the technical condition of a conduit into the calculation process, and thus bring the obtained values closer to the real values.

The algorithm proposed in the ASTM guidelines introduces a reduction factor that results from the ovalisation of the cross-section and also a coefficient that takes into account the presence of the existing pipeline, which is a casing for the lining - this has a significant impact on the value of the load capacity of the structure. The coefficient that takes into account the existence of a casing (pipeline) enables the cross-section to be considered as a complex system consisting of the existing pipe and the lining that is installed inside it.

The RERAU formula also takes into account the deformation of the existing conduit. These are the values that characterise the size of the annular space and the ovalisation of the conduit. The RERAU formula includes two types of geometrical irregularities of the cross-section. However, there is no connection between the load-bearing capacity of the liner and the existing conduit.

The value of the critical pressure in the SRM WRc method is determined from a simple relationship, which, apart from geometric characteristics, takes into account the horizontal deformation of the existing conduit's crosssection. The formula also includes a safety factor, the value of which for CIPP linings is assumed to be equal to 2 .

All the basic imperfections of a conduit's cross-section were taken into account in the DWA guidelines. The value of the permissible critical pressure depends directly on the value of local deformation, ovalisation, and the annular gap. Moreover, as in any other algorithm, the value of permissible pressure $p_{c r}$ depends on the geometric and material parameters of the installed lining. The division of pipelines, which results from their technical condition and which is used in the guidelines, determines the possibilities of using various renovation techniques and specifies the types of external loads that should be taken into account in calculations. The range of loads depends on the adopted technical condition and takes into account the cooperation, or lack of, between the lining and the existing pipeline.

\section{Results obtained for each engineering algorithms used in practice}

As part of this research and scientific work, calculations of the permissible critical pressure values obtained using all the above-described calculation algorithms were performed. The correct determination of the constructional and material parameters of the CIPP repair lining results from the properly calculated value of the permissible external pressure that may act on the lining, and also from taking into account, or not, its casing in the form of an existing pipeline. The seemingly uncomplicated value of the permissible external pressure $p_{c r}$ depends on several independent variables, such as:

- the assessment of the technical condition of the sewer which is to be repaired - imperfection values,

- values that characterise the material properties of the liner,

- values of external loads. 


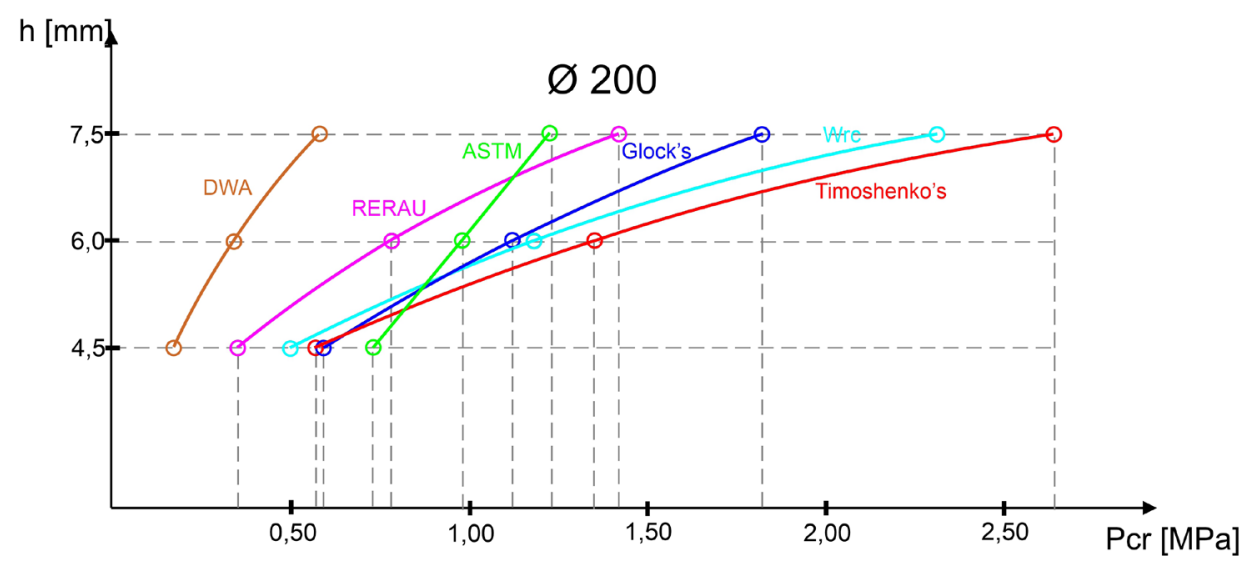

Figure 4: The value of critical pressure $\mathrm{p}_{\mathrm{cr}}$ for DN200.

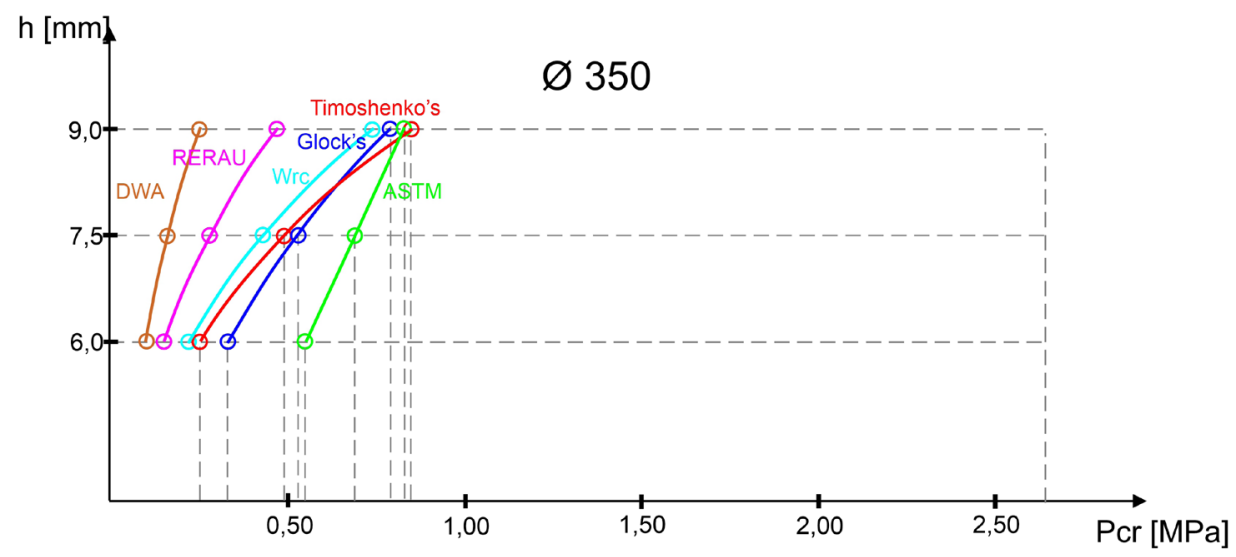

Figure 5: The value of critical pressure $p_{c r}$ for DN350.

As the research studies previously mentioned show, only the precise determination of the above values guarantees the correct results of the permissible critical pressure $\mathrm{p}_{\mathrm{cr}}$, and thus the correct selection of the design solution, i.e. the correct repair technology and the material intended for implementation.

The calculations were performed for laboratory-tested sample models, which was shown in the first part of article [7]. The obtained results are summarised in Table 2 and in Figures 4, 5, and 6 - separately for each diameter.

In the course of the analysis of the calculation results, the results obtained using the DWA-ATV algorithm were adopted as the maximum permissible critical pressure. These values are defined as $100 \%$ of the permissible external critical pressure $\mathrm{p}_{\mathrm{cr}}$ (see Table 3).

The highest values of critical pressure were obtained using the Glock and Timoshenko algorithms. They exceed several times the values obtained from the calculations based on the DWA guidelines [6]. Moreover, all the values calculated according to individual algorithms differ significantly, which mainly results from the reduction factors that are included in these formulas. The values of the permissible pressure $\mathrm{p}_{\mathrm{cr}}$ decrease in the case of the original Timoshenko and Glock algorithms when compared to the algorithm proposed in the DWA guidelines. The percentage differences are shown in Table 3.

\section{FEM method}

\subsection{Application of the FEM}

With regard to the need to optimise the process of selecting the strength parameters of liners, as well as the need to verify the correctness of laboratory tests and their results, a series of analyses using the FEM was performed. The 


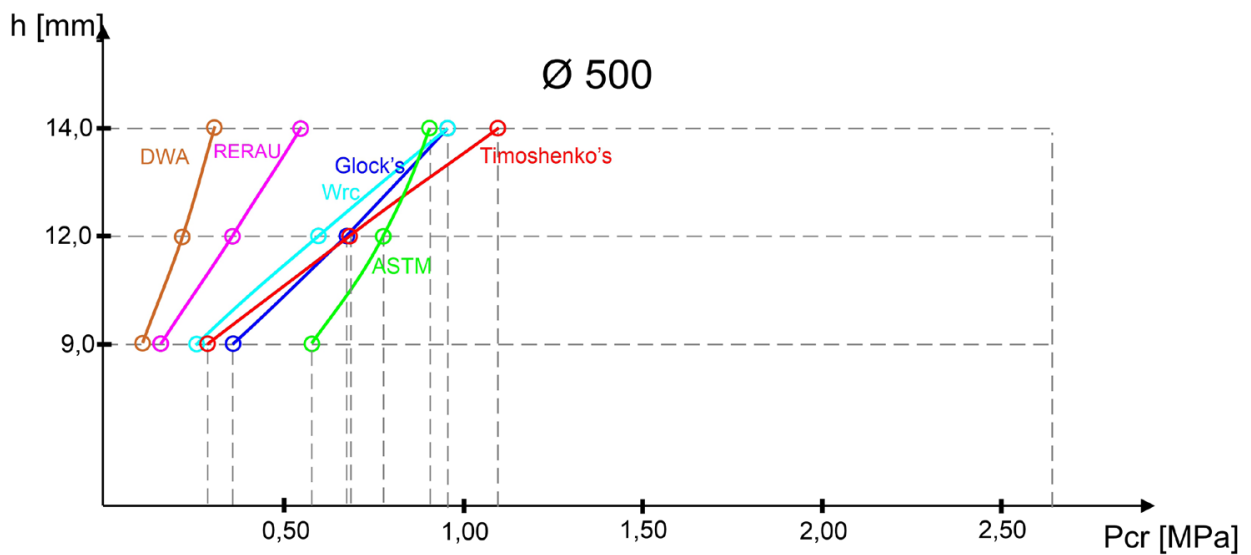

Figure 6: The value of critical pressure $\mathrm{p}_{\mathrm{cr}}$ for DN500.

Table 2: Results of calculation algorithm.

\begin{tabular}{|c|c|c|c|c|c|c|c|c|c|c|}
\hline \multirow{3}{*}{$\begin{array}{l}\text { Sample } \\
\text { no. }\end{array}$} & \multirow{2}{*}{$\begin{array}{l}\text { Liner thickness } \\
\text { h }\end{array}$} & \multirow[t]{2}{*}{ Diameter } & \multirow[t]{2}{*}{ Radius } & \multicolumn{7}{|c|}{ Calculation algorithm } \\
\hline & & & & Timo- shenko`s & Glock`s & ASTM & WRc & RERAU & ATV & $143-2$ \\
\hline & [m] & & & \multicolumn{7}{|c|}{ critical pressure $p_{c r} N / m^{2}$} \\
\hline 1 & 0,0045 & 0,200 & 0,100 & 0,57 & 0,59 & 0,73 & 0,50 & 0,35 & 0,17 & \\
\hline 2 & 0,0060 & 0,200 & 0,100 & 1,35 & 1,12 & 0,98 & 1,18 & 0,78 & 0,34 & \\
\hline 3 & 0,0075 & 0,200 & 0,100 & 2,64 & 1,82 & 1,23 & 2,31 & 1,42 & 0,58 & \\
\hline 4 & 0,0060 & 0,350 & 0,175 & 0,25 & 0,33 & 0,55 & 0,22 & 0,15 & 0,10 & \\
\hline 5 & 0,0075 & 0,350 & 0,175 & 0,49 & 0,53 & 0,69 & 0,43 & 0,28 & 0,16 & \\
\hline 6 & 0,0090 & 0,350 & 0,175 & 0,85 & 0,79 & 0,83 & 0,74 & 0,47 & 0,25 & \\
\hline 7 & 0,0090 & 0,500 & 0,250 & 0,29 & 0,36 & 0,58 & 0,26 & 0,16 & 0,11 & \\
\hline 8 & 0,0120 & 0,500 & 0,250 & 0,69 & 0,68 & 0,78 & 0,60 & 0,36 & 0,22 & \\
\hline 9 & 0,0140 & 0,500 & 0,250 & 1,10 & 0,96 & 0,91 & 0,96 & 0,55 & 0,31 & \\
\hline
\end{tabular}

Table 3: Percentage differences of results in each algorithm.

\begin{tabular}{|c|c|c|c|c|c|c|c|}
\hline \multirow[t]{2}{*}{ No. } & \multirow{2}{*}{$\begin{array}{l}\text { Diameter } \\
{[\mathrm{mm}]}\end{array}$} & \multicolumn{6}{|c|}{ Calculation algorithm } \\
\hline & & Timo shenko`s & Glock`s & ASTM & WRc & RERAU & DVWK-ATV \\
\hline 1 & 200 & $333,64 \%$ & $347,14 \%$ & $425,28 \%$ & $291,81 \%$ & $206,21 \%$ & $100,00 \%$ \\
\hline 2 & & $400,47 \%$ & $331,02 \%$ & $289,36 \%$ & $350,26 \%$ & $231,46 \%$ & \\
\hline 3 & & $456,26 \%$ & $315,47 \%$ & $212,63 \%$ & $399,05 \%$ & $245,70 \%$ & \\
\hline 4 & 350 & $263,21 \%$ & $340,42 \%$ & $574,81 \%$ & $230,21 \%$ & $154,02 \%$ & \\
\hline 5 & & $306,53 \%$ & $331,63 \%$ & $430,29 \%$ & $268,09 \%$ & $175,18 \%$ & \\
\hline 6 & & $345,17 \%$ & $322,74 \%$ & $337,96 \%$ & $301,88 \%$ & $191,19 \%$ & \\
\hline 7 & 500 & $261,29 \%$ & $324,99 \%$ & $518,01 \%$ & $228,53 \%$ & $140,09 \%$ & \\
\hline 8 & & $316,77 \%$ & $313,00 \%$ & $355,42 \%$ & $277,05 \%$ & $164,65 \%$ & \\
\hline 9 & & $349,33 \%$ & $305,13 \%$ & $289,15 \%$ & $305,53 \%$ & $176,56 \%$ & \\
\hline
\end{tabular}



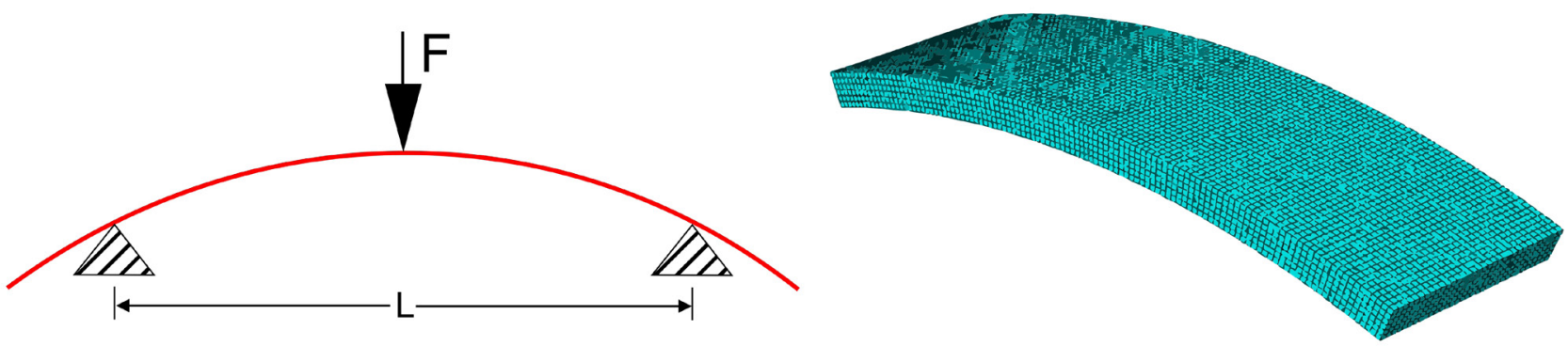

Figure 7: Static scheme (L=16h, see Fig. 1).

FEM was used to build the model of the previously tested liner sample.

The analyses were carried out on nine spatial models. The models were parameterised in order for them to represent the tested shell as accurately as possible. The Abaqus system [24] was used to perform the calculations, which were carried out in the Wroclaw Centre for Networking and Supercomputing (http://www.wcss.pl), grant No. 319.

\subsection{Numerical analyses}

The computational model was built on the basis of the assumptions that are commonly used in this type of scientific analysis and that refer to the material's parameters and their interactions. The correct construction of the discrete model required the determination of the quantities that enable the parameterisation of the task. Parameterisation was made primarily on the basis of density $-1.5 \mathrm{t} / \mathrm{m}^{3}$, modulus of elasticity $-2.5 \mathrm{GPa}$, and Poisson's ratio -0.3 .

The homogeneity of the material structure of the tested samples made it possible to use the basic material parameters (indicated above) describing its properties - it was fully sufficient for the purposes of comparison in the results of engineering calculations.

In the considered computational case, a threedimensional (3D) model was used to imitate the actual conditions of testing the liner samples. The basic finite element was the theta-type element. It is a three-node spatial tetrahedral solid element that is used for structural model analysis. There are three degrees of freedom in each element node, in the form of three offsets. The used elements allowed for the optimisation of the numerical model and enabled the linear variability of stresses for the entire task. In the ABAQUS system, the shell thickness of an element is defined by the thickness in nodes, which varies linearly between adjacent nodes. The support elements were defined as a pinned support with the following parameters: $\mathrm{U} 1=\mathrm{U} 2=\mathrm{U} 3=0$, and rotations UR1 $=\mathrm{UR} 2=0$. The static scheme and the discrete model are shown in Figure 7.

\subsection{Results of numerical analyses for a model of a liner with a diameter of $200 \mathrm{~mm}$}

Numerical analyses were performed for two stages of three-point bending (see Tables 4, 5, and 6, where $\mathrm{h}$ is thickness of the liner, and $\mathrm{F}_{1}$ and $\mathrm{F}_{2}$ are the force values corresponding to the deflection $\mathrm{s}_{1}$ and $\mathrm{s}_{2}$, respectively). In the first stage, the obtained results differed significantly from the results of laboratory tests for the equivalent stage of bending the sample. The differences for individual samples reached values exceeding even $40 \%$ (see Table 4). This situation is probably related to the heterogeneity of the CIPP liner samples, which were taken from the place of their installation, as well as the following:

- small geometric deformations,

- thickness variation,

- "adjustment" (effect of matching to the supports of the testing machine) of the sample during the initial loading phase,

- inhomogeneous supersaturation of the liner samples with resin.

All the above-mentioned irregularities do not occur in the numerical model, hence the differences between the obtained deflection values of the discrete model and the real sample. This fact is confirmed by the reduction of differences in the obtained results for the next phase of loading the samples - here the maximum values of the differences did not exceed 13\% (see Table 6). Figures 8 and 9 show the values of deflections for the individual loading phases of the model. 
Table 4: Comparison of results of numerical analyses and laboratory tests for a model of a liner with a diameter of $200 \mathrm{~mm}$ and $4,50 \mathrm{~mm}$ wall thickness.

\begin{tabular}{|c|c|c|c|c|c|c|c|c|c|c|}
\hline \multirow[t]{4}{*}{ No. } & \multirow[t]{4}{*}{$\mathrm{h}[\mathrm{mm}]$} & \multirow{4}{*}{$\begin{array}{l}\mathbf{L} \\
{[\mathrm{mm}]}\end{array}$} & \multicolumn{4}{|c|}{ Stage of deformation - $0,05 \%$} & \multicolumn{4}{|c|}{ Stage of deformation - $0,25 \%$} \\
\hline & & & \multicolumn{8}{|c|}{ according to PN-EN ISO 178:2019-06 [9] } \\
\hline & & & \multirow{2}{*}{$\overline{F_{1}[N]}$} & Lab. tests & FEM & \multirow[t]{2}{*}{ difference } & \multirow[t]{2}{*}{$\mathrm{F}_{2}[\mathrm{~N}]$} & Lab. tests & FEM & \multirow[t]{2}{*}{ difference } \\
\hline & & & & \multicolumn{2}{|l|}{$\mathrm{s}_{1}[\mathrm{~mm}]$} & & & \multicolumn{2}{|l|}{$\mathbf{s}_{2}[\mathrm{~mm}]$} & \\
\hline 1 & 4,60 & 73,60 & 8,25 & 1,13 & 0,95 & $18,63 \%$ & 230,20 & 2,82 & 3,04 & $-7,32 \%$ \\
\hline 2 & 4,70 & 75,20 & 8,41 & 1,38 & 0,97 & $42,37 \%$ & 230,10 & 2,94 & 3,04 & $-3,21 \%$ \\
\hline 3 & 4,50 & 72,00 & 8,03 & 1,57 & 0,92 & $70,27 \%$ & 227,50 & 3,26 & 3,00 & $8,64 \%$ \\
\hline 4 & 4,60 & 73,60 & 8,21 & 1,03 & 0,95 & $9,27 \%$ & 227,10 & 2,63 & 3,00 & $-12,32 \%$ \\
\hline 5 & 4,70 & 75,20 & 8,38 & 1,19 & 0,96 & $23,83 \%$ & 224,40 & 2,76 & 2,96 & $-6,95 \%$ \\
\hline 6 & 4,70 & 75,20 & 8,39 & 1,38 & 0,97 & $42,71 \%$ & 222,10 & 2,76 & 2,93 & $-5,99 \%$ \\
\hline Ave. & 4,63 & 74,13 & 8,28 & 1,28 & 0,95 & $34,39 \%$ & 226,90 & 2,86 & 3,00 & $-4,51 \%$ \\
\hline
\end{tabular}

Table 5: Comparison of results of numerical analyses and laboratory tests for a model of a liner with a diameter of $200 \mathrm{~mm}$ and $6,00 \mathrm{~mm}$ wall thickness.

\begin{tabular}{|c|c|c|c|c|c|c|c|c|c|c|}
\hline \multirow[t]{4}{*}{ No. } & \multirow[t]{4}{*}{$h[\mathrm{~mm}]$} & \multirow{4}{*}{$\begin{array}{l}\mathrm{L} \\
{[\mathrm{mm}]}\end{array}$} & \multirow{2}{*}{\multicolumn{8}{|c|}{$\begin{array}{l}\text { Stage of deformation - 0,05\% } \\
\text { according to PN-EN ISO 178:2019-06 [9] }\end{array}$}} \\
\hline & & & & & & & & & & \\
\hline & & & \multirow[t]{2}{*}{$\overline{F_{1}[N]}$} & Lab. tests & FEM & \multirow[t]{2}{*}{ difference } & \multirow[t]{2}{*}{$\mathrm{F}_{2}[\mathrm{~N}]$} & Lab. tests & FEM & \multirow[t]{2}{*}{ difference } \\
\hline & & & & \multicolumn{2}{|l|}{$\mathrm{s}_{1}[\mathrm{~mm}]$} & & & \multicolumn{2}{|l|}{$\mathrm{s}_{2}[\mathrm{~mm}]$} & \\
\hline 1 & 6,10 & 97,60 & 8,32 & 1,13 & 0,92 & $23,16 \%$ & 242,1 & 2,92 & 3,10 & $-5,78 \%$ \\
\hline 2 & 6,20 & 99,20 & 8,12 & 1,09 & 0,90 & $21,40 \%$ & 240,1 & 2,73 & 3,07 & $-11,36 \%$ \\
\hline 3 & 6,10 & 97,60 & 8,06 & 1,16 & 0,89 & $29,96 \%$ & 238,1 & 3,02 & 3,05 & $-0,89 \%$ \\
\hline 4 & 6,00 & 96,00 & 8,16 & 1,15 & 0,90 & $27,67 \%$ & 242,1 & 3,05 & 3,10 & $-1,73 \%$ \\
\hline 5 & 6,30 & 100,80 & 8,25 & 1,15 & 0,91 & $25,61 \%$ & 240,5 & 2,85 & 3,08 & $-7,37 \%$ \\
\hline 6 & 6,10 & 97,60 & 8,41 & 1,03 & 0,93 & $11,02 \%$ & 241,2 & 2,85 & 3,09 & $-7,87 \%$ \\
\hline Ave. & 6,13 & 98,13 & 8,22 & 1,12 & 0,91 & $23,07 \%$ & 240,68 & 2,90 & 3,08 & $-5,84 \%$ \\
\hline
\end{tabular}

Table 6: Comparison of results of numerical analyses and laboratory tests for a model of a liner with a diameter of $200 \mathrm{~mm}$ and $7,50 \mathrm{~mm}$ wall thickness.

\begin{tabular}{|c|c|c|c|c|c|c|c|c|c|c|}
\hline \multirow[t]{4}{*}{ No. } & \multirow[t]{4}{*}{$\mathrm{h}[\mathrm{mm}]$} & \multirow{4}{*}{$\begin{array}{l}\mathbf{L} \\
{[\mathrm{mm}]}\end{array}$} & \multicolumn{4}{|c|}{ Stage of deformation $-0,05 \%$} & \multicolumn{4}{|c|}{ Stage of deformation $-0,25 \%$} \\
\hline & & & \multicolumn{8}{|c|}{ according to PN-EN ISO 178:2019-06 [9] } \\
\hline & & & \multirow[t]{2}{*}{$\mathrm{F}_{1}[\mathrm{~N}]$} & Lab. tests & FEM & \multirow[t]{2}{*}{ difference } & \multirow[t]{2}{*}{$\mathrm{F}_{2}[\mathrm{~N}]$} & Lab. tests & FEM & \multirow[t]{2}{*}{ difference } \\
\hline & & & & \multicolumn{2}{|l|}{$\mathrm{s}_{1}[\mathrm{~mm}]$} & & & \multicolumn{2}{|l|}{$\mathbf{s}_{2}[\mathrm{~mm}]$} & \\
\hline 1 & 7,60 & 121,60 & 8,70 & 0,95 & 0,82 & $15,53 \%$ & 255,00 & 2,91 & 3,20 & $-9,21 \%$ \\
\hline 2 & 7,70 & 123,20 & 8,65 & 0,97 & 0,82 & $18,51 \%$ & 253,50 & 2,87 & 3,18 & $-9,86 \%$ \\
\hline 3 & 7,50 & 120,00 & 8,55 & 0,90 & 0,81 & $11,19 \%$ & 256,20 & 2,82 & 3,22 & $-12,41 \%$ \\
\hline 4 & 7,60 & 121,60 & 8,74 & 0,92 & 0,82 & $11,17 \%$ & 251,50 & 2,75 & 3,16 & $-12,95 \%$ \\
\hline 5 & 7,70 & 123,20 & 8,61 & 1,03 & 0,81 & $26,75 \%$ & 255,60 & 2,87 & 3,21 & $-10,60 \%$ \\
\hline 6 & 7,50 & 120,00 & 8,52 & 0,99 & 0,80 & $23,53 \%$ & 253,80 & 3,04 & 3,18 & $-4,55 \%$ \\
\hline Ave. & 7,60 & 121,60 & 8,63 & 0,96 & 0,81 & $17,76 \%$ & 254,27 & 2,87 & 3,19 & $-9,93 \%$ \\
\hline
\end{tabular}



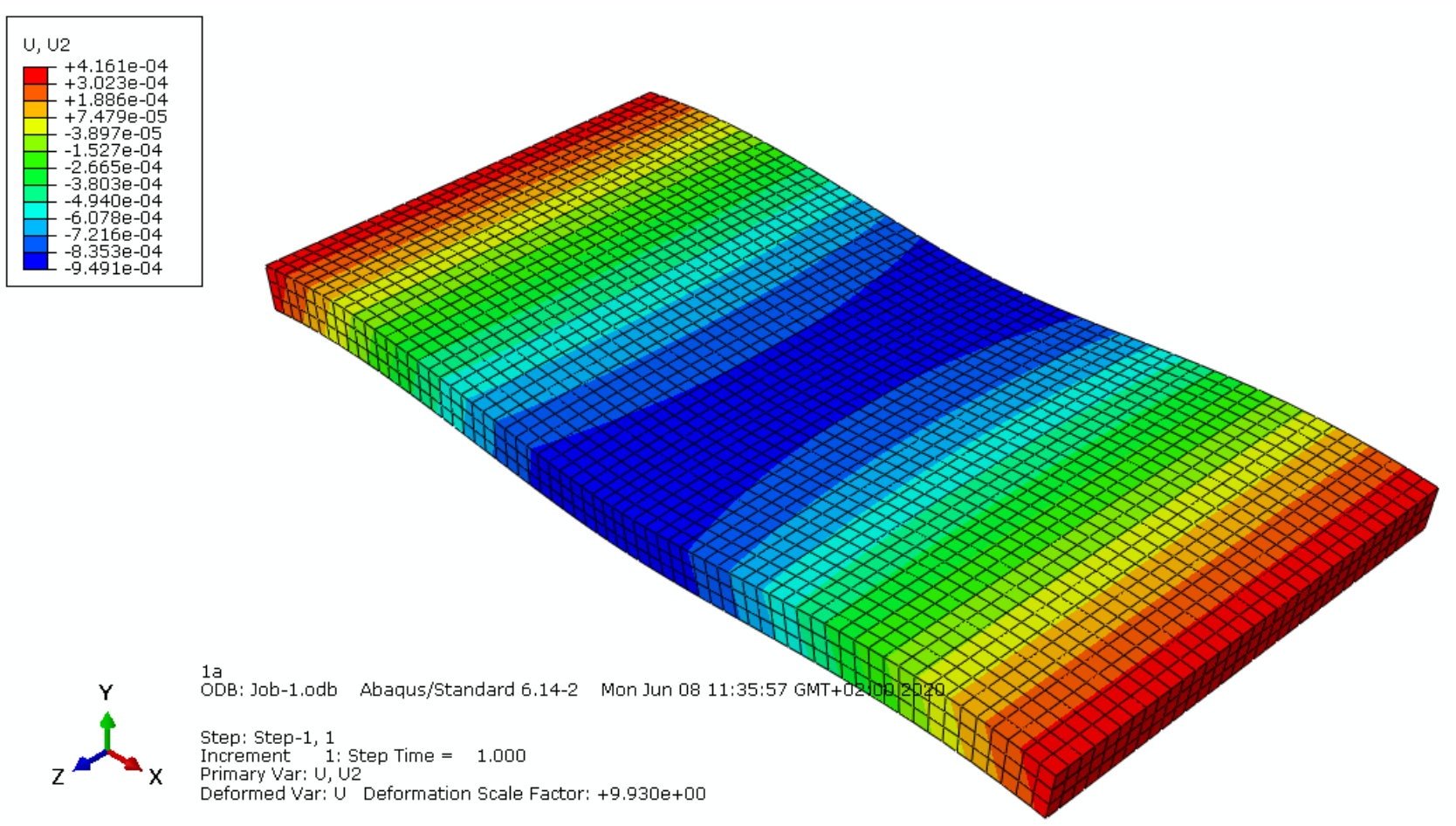

Figure 8: Example deflections for the force $F_{1}(0.05 \%)$.
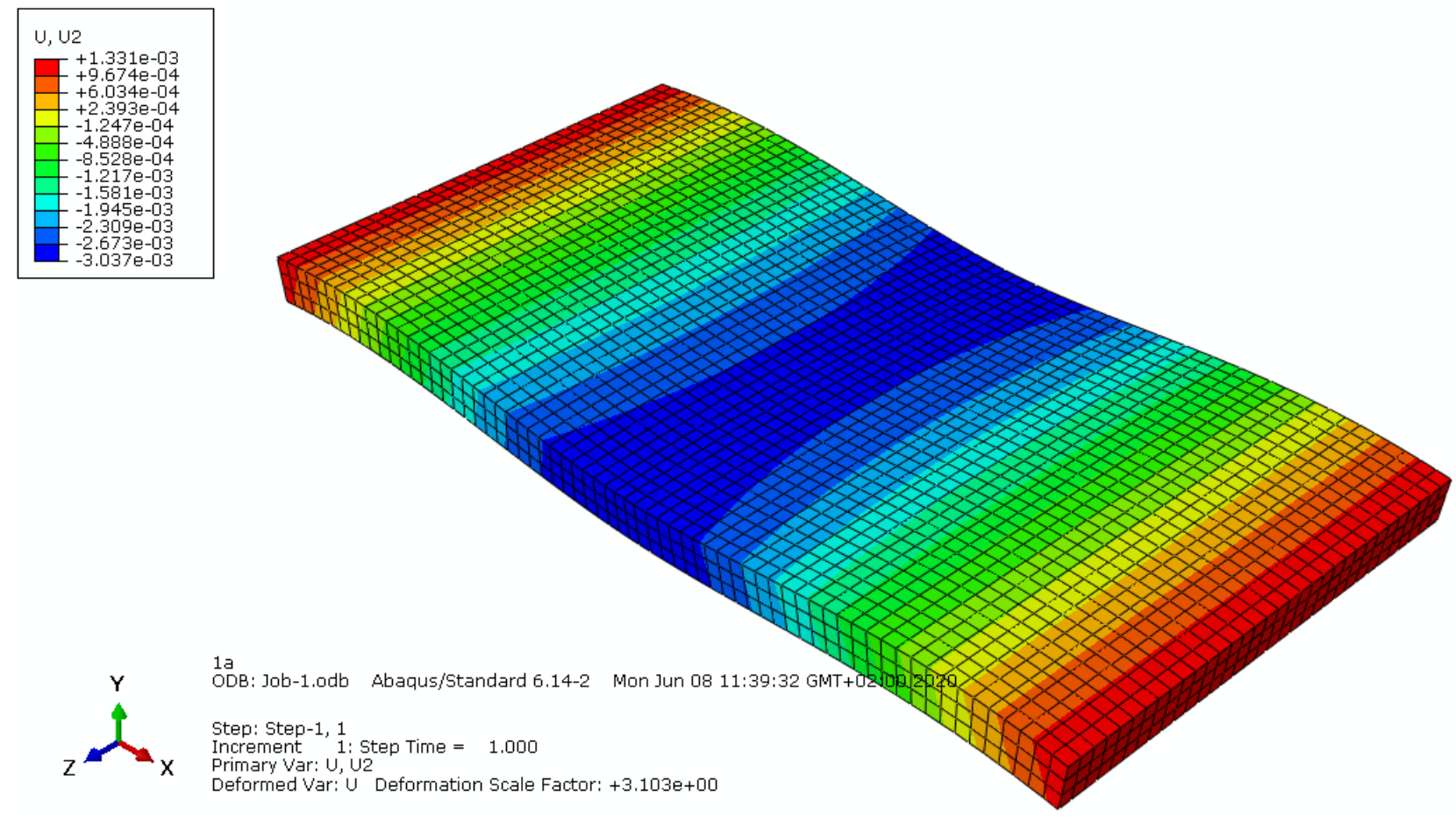

Figure 9: Example deflections for the force $F_{2}(0.25 \%)$. 
Table 7: Comparison of results of numerical analyses and laboratory tests for a model of a liner with a diameter of $350 \mathrm{~mm}$ and $6,00 \mathrm{~mm}$ wall thickness.

\begin{tabular}{|c|c|c|c|c|c|c|c|c|c|c|}
\hline \multirow[t]{4}{*}{ No. } & \multirow[t]{4}{*}{$\mathrm{h}[\mathrm{mm}]$} & \multirow{4}{*}{$\begin{array}{l}\mathbf{L} \\
{[\mathrm{mm}]}\end{array}$} & \multicolumn{4}{|c|}{ Stage of deformation - $0,05 \%$} & \multicolumn{4}{|c|}{ Stage of deformation $-0,25 \%$} \\
\hline & & & \multicolumn{8}{|c|}{ according to PN-EN ISO 178:2019-06 [9] } \\
\hline & & & \multirow[t]{2}{*}{$\mathrm{F}_{1}[\mathrm{~N}]$} & Lab. tests & FEM & \multirow[t]{2}{*}{ difference } & \multirow[t]{2}{*}{$\mathrm{F}_{2}[\mathrm{~N}]$} & Lab. tests & FEM & \multirow[t]{2}{*}{ difference } \\
\hline & & & & \multicolumn{2}{|l|}{$\mathrm{s}_{1}[\mathrm{~mm}]$} & & & \multicolumn{2}{|l|}{$\mathbf{s}_{2}[\mathrm{~mm}]$} & \\
\hline 1 & 6,10 & 97,60 & 8,31 & 1,03 & 0,92 & $12,22 \%$ & 242,00 & 2,77 & 3,00 & $-7,67 \%$ \\
\hline 2 & 6,20 & 99,20 & 8,41 & 1,04 & 0,90 & $15,61 \%$ & 243,20 & 2,85 & 3,01 & $-5,50 \%$ \\
\hline 3 & 6,00 & 96,00 & 8,36 & 1,02 & 0,93 & $10,64 \%$ & 244,10 & 3,02 & 3,03 & $-0,17 \%$ \\
\hline 4 & 6,20 & 99,20 & 8,28 & 0,97 & 0,92 & $5,40 \%$ & 242,10 & 2,73 & 3,00 & $-9,20 \%$ \\
\hline 5 & 6,30 & 100,80 & 8,36 & 1,00 & 0,93 & $8,00 \%$ & 243,50 & 2,66 & 3,02 & $-11,96 \%$ \\
\hline 6 & 6,00 & 96,00 & 8,42 & 1,02 & 0,93 & $9,85 \%$ & 241,50 & 2,87 & 2,99 & $-4,23 \%$ \\
\hline Ave. & 6,13 & 98,13 & 8,36 & 1,01 & 0,92 & $10,27 \%$ & 242,73 & 2,81 & 3,01 & $-6,45 \%$ \\
\hline
\end{tabular}

Table 8: Comparison of results of numerical analyses and laboratory tests for a model of a liner with a diameter of $350 \mathrm{~mm}$ and 7,50mm wall thickness.

\begin{tabular}{|c|c|c|c|c|c|c|c|c|c|c|}
\hline \multirow[t]{4}{*}{ No. } & \multirow[t]{4}{*}{$\mathrm{h}[\mathrm{mm}]$} & \multirow{4}{*}{$\begin{array}{l}\mathrm{L} \\
{[\mathrm{mm}]}\end{array}$} & \multicolumn{4}{|c|}{ Stage of deformation $-0,05 \%$} & \multicolumn{4}{|c|}{ Stage of deformation $-0,25 \%$} \\
\hline & & & \multicolumn{8}{|c|}{ according to PN-EN ISO 178:2019-06 [9] } \\
\hline & & & \multirow[t]{2}{*}{$\mathrm{F}_{1}[\mathrm{~N}]$} & Lab. test & FEM & \multirow[t]{2}{*}{ difference } & \multirow[t]{2}{*}{$\mathrm{F}_{2}[\mathrm{~N}]$} & Lab. tests & FEM & \multirow[t]{2}{*}{ difference } \\
\hline & & & & \multicolumn{2}{|l|}{$\mathbf{s}_{1}[\mathrm{~mm}]$} & & & \multicolumn{2}{|l|}{$\mathbf{s}_{2}[\mathrm{~mm}]$} & \\
\hline 1 & 7,50 & 120,00 & 8,56 & 1,12 & 0,90 & $24,44 \%$ & 246,00 & 3,10 & 3,10 & $0,13 \%$ \\
\hline 2 & 7,60 & 121,60 & 8,60 & 0,95 & 0,90 & $4,77 \%$ & 247,60 & 2,94 & 3,12 & $-5,88 \%$ \\
\hline 3 & 7,70 & 123,20 & 8,59 & 1,18 & 0,90 & $31,14 \%$ & 246,50 & 2,96 & 3,11 & $-4,68 \%$ \\
\hline 4 & 7,60 & 121,60 & 8,61 & 1,23 & 0,91 & $36,05 \%$ & 248,20 & 3,06 & 3,13 & $-2,06 \%$ \\
\hline 5 & 7,50 & 120,00 & 8,62 & 1,15 & 0,91 & $27,11 \%$ & 246,80 & 2,98 & 3,11 & $-4,31 \%$ \\
\hline 6 & 7,40 & 118,40 & 8,55 & 1,17 & 0,90 & $29,88 \%$ & 248,90 & 3,18 & 3,14 & $1,33 \%$ \\
\hline Ave. & 7,55 & 120,80 & 8,59 & 1,13 & 0,90 & $25,56 \%$ & 247,33 & 3,04 & 3,12 & $-2,57 \%$ \\
\hline
\end{tabular}

\subsection{Results of numerical analyses for a model of a liner with a diameter of $350 \mathrm{~mm}$}

As was the case with the samples with a diameter of DN200, very large discrepancies were observed in the results obtained in the initial phase of loading the sample. In the case of the DN350 diameter, the difference between the results of laboratory tests and numerical analyses in the first stage of loading the sample was over 50\% (see Table 9). Similar as for the samples with a smaller diameter, with an increase in the load value, the difference in the obtained values decreases to about $10 \%$. This is also confirmed by the fact that the sample "adjusts" on the machine during laboratory tests. The results of the analyses are presented in Tables 7, 8, and 9.

\subsection{Results of numerical analyses for a model of a liner with a diameter of $500 \mathrm{~mm}$}

Comparative analysis of the laboratory tests with the numerical calculations, which were performed for samples with a diameter of DN500 mm, showed significantly greater differences than in the case of liner samples with smaller diameters - the differences in the first phase of loading the sample exceeded the value of $100 \%$ (see Table 12). Similarly to the previous cases, the increase in load reduces the discrepancy of the obtained deflection values. The differences in the second stage of loading the samples amount on average to about $10 \%$. The results of the analyses are presented in Tables 10, 11, and 12. 
Table 9: Comparison of results of numerical analyses and laboratory tests for a model of a liner with a diameter of $350 \mathrm{~mm}$ and 9,00mm wall thickness.

\begin{tabular}{|c|c|c|c|c|c|c|c|c|c|c|}
\hline \multirow[t]{4}{*}{ No. } & \multirow[t]{4}{*}{$\mathrm{h}[\mathrm{mm}]$} & \multirow{4}{*}{$\begin{array}{l}\mathrm{L} \\
{[\mathrm{mm}]}\end{array}$} & \multicolumn{4}{|c|}{ Stage of deformation - $0,05 \%$} & \multicolumn{4}{|c|}{ Stage of deformation - $0,25 \%$} \\
\hline & & & \multicolumn{8}{|c|}{ according to PN-EN ISO 178:2019-06 [9] } \\
\hline & & & \multirow[t]{2}{*}{$\mathrm{F}_{1}[\mathrm{~N}]$} & Lab. Tests & FEM & \multirow[t]{2}{*}{ difference } & \multirow[t]{2}{*}{$\mathrm{F}_{2}[\mathrm{~N}]$} & \multirow{2}{*}{\multicolumn{2}{|c|}{$\begin{array}{ll}\text { Lab. Tests } & \text { FEM } \\
\mathbf{s}_{2}[\mathrm{~mm}] & \\
\end{array}$}} & \multirow[t]{2}{*}{ difference } \\
\hline & & & & $\mathbf{s}_{1}[\mathrm{~mm}]$ & & & & & & \\
\hline 1 & 9,10 & 145,60 & 8,75 & 1,33 & 0,87 & $52,79 \%$ & 260,00 & 3,27 & 3,49 & $-6,42 \%$ \\
\hline 2 & 9,20 & 147,20 & 8,76 & 1,13 & 0,87 & $29,39 \%$ & 261,00 & 3,12 & 3,50 & $-11,00 \%$ \\
\hline 3 & 9,00 & 144,00 & 8,79 & 1,34 & 0,87 & $53,78 \%$ & 262,50 & 3,34 & 3,52 & $-5,19 \%$ \\
\hline 4 & 9,30 & 148,80 & 8,86 & 1,34 & 0,88 & $51,86 \%$ & 259,80 & 3,27 & 3,49 & $-6,23 \%$ \\
\hline 5 & 9,00 & 144,00 & 8,89 & 1,34 & 0,88 & $52,05 \%$ & 259,50 & 3,34 & 3,48 & $-4,09 \%$ \\
\hline 6 & 9,10 & 145,60 & 8,85 & 1,37 & 0,88 & $55,37 \%$ & 261,20 & 3,34 & 3,51 & $-4,68 \%$ \\
\hline Ave. & 9,12 & 145,86 & 8,82 & 1,31 & 0,88 & $49,23 \%$ & 260,67 & 3,28 & 3,50 & $-6,27 \%$ \\
\hline
\end{tabular}

Table 10: Comparison of results of numerical analyses and laboratory tests for a model of a liner with a diameter of $500 \mathrm{~mm}$ and $9,00 \mathrm{~mm}$ wall thickness.

\begin{tabular}{|c|c|c|c|c|c|c|c|c|c|c|}
\hline \multirow[t]{4}{*}{ No. } & \multirow[t]{4}{*}{$\mathrm{h}[\mathrm{mm}]$} & \multirow{4}{*}{$\begin{array}{l}\mathbf{L} \\
{[\mathrm{mm}]}\end{array}$} & \multicolumn{4}{|c|}{ Stage of deformation - $0,05 \%$} & \multicolumn{4}{|c|}{ Stage of deformation - $0,25 \%$} \\
\hline & & & \multicolumn{8}{|c|}{ according to PN-EN ISO 178:2019-06 [9] } \\
\hline & & & & Lab. Tests & FEM & difference & & Lab. Tests & FEM & difference \\
\hline & & & $\overline{F_{1}[N]}$ & \multicolumn{2}{|l|}{$\mathrm{s}_{1}[\mathrm{~mm}]$} & & $\mathrm{F}_{2}[\mathrm{~N}]$ & \multicolumn{2}{|l|}{$\mathrm{s}_{2}[\mathrm{~mm}]$} & \\
\hline 1 & 9,00 & 144,00 & 8,85 & 1,34 & 1,22 & $10,16 \%$ & 290,00 & 3,72 & 3,83 & $-2,75 \%$ \\
\hline 2 & 9,10 & 145,60 & 8,89 & 1,33 & 1,23 & $8,46 \%$ & 295,60 & 3,61 & 3,90 & $-7,58 \%$ \\
\hline 3 & 9,20 & 147,20 & 8,91 & 1,35 & 1,23 & $10,10 \%$ & 296,10 & 3,49 & 3,91 & $-10,66 \%$ \\
\hline 4 & 9,30 & 148,80 & 8,82 & 1,34 & 1,22 & $10,03 \%$ & 267,10 & 3,23 & 3,53 & $-8,35 \%$ \\
\hline 5 & 9,00 & 144,00 & 8,89 & 1,38 & 1,23 & $12,80 \%$ & 292,20 & 3,57 & 3,86 & $-7,46 \%$ \\
\hline 6 & 9,10 & 145,60 & 8,85 & 1,33 & 1,22 & $8,95 \%$ & 293,50 & 3,53 & 3,88 & $-8,88 \%$ \\
\hline Ave. & 9,12 & 145,86 & 8,87 & 1,35 & 1,22 & $10,09 \%$ & 289,08 & 3,53 & 3,82 & $-7,62 \%$ \\
\hline
\end{tabular}

Table 11: Comparison of results of numerical analyses and laboratory tests for a model of a liner with a diameter of $500 \mathrm{~mm}$ and $12,00 \mathrm{~mm}$ wall thickness.

\begin{tabular}{|c|c|c|c|c|c|c|c|c|c|c|}
\hline \multirow[t]{4}{*}{ No. } & \multirow[t]{4}{*}{$\mathrm{h}[\mathrm{mm}]$} & \multirow{4}{*}{$\begin{array}{l}\mathbf{L} \\
{[\mathrm{mm}]}\end{array}$} & \multicolumn{4}{|c|}{ Stage of deformation - $0,05 \%$} & \multicolumn{4}{|c|}{ Stage of deformation - $0,25 \%$} \\
\hline & & & \multicolumn{8}{|c|}{ according to PN-EN ISO 178:2019-06 [9] } \\
\hline & & & \multirow[t]{2}{*}{$\mathrm{F}_{1}[\mathrm{~N}]$} & Lab. tests & FEM & \multirow[t]{2}{*}{ difference } & \multirow[t]{2}{*}{$\mathrm{F}_{2}[\mathrm{~N}]$} & Lab. tests & FEM & \multirow[t]{2}{*}{ difference } \\
\hline & & & & \multicolumn{2}{|l|}{$\mathrm{s}_{1}[\mathrm{~mm}]$} & & & \multicolumn{2}{|l|}{$\mathrm{s}_{2}[\mathrm{~mm}]$} & \\
\hline 1 & 12,00 & 192,00 & 9,10 & 1,69 & 1,10 & $53,60 \%$ & 320,00 & 4,15 & 4,50 & $-7,84 \%$ \\
\hline 2 & 12,20 & 195,20 & 9,32 & 1,76 & 1,13 & $56,46 \%$ & 321,20 & 4,03 & 4,52 & $-10,80 \%$ \\
\hline 3 & 12,30 & 196,80 & 9,15 & 1,75 & 1,11 & $58,07 \%$ & 325,20 & 4,10 & 4,57 & $-10,43 \%$ \\
\hline 4 & 12,10 & 193,60 & 9,12 & 1,73 & 1,10 & $56,60 \%$ & 321,50 & 4,01 & 4,52 & $-11,27 \%$ \\
\hline 5 & 12,00 & 192,00 & 9,00 & 1,89 & 1,09 & $74,13 \%$ & 325,60 & 4,40 & 4,58 & $-3,83 \%$ \\
\hline 6 & 12,40 & 198,40 & 8,95 & 1,68 & 1,08 & $55,72 \%$ & 318,60 & 3,96 & 4,48 & $-11,53 \%$ \\
\hline Ave. & 12,17 & 194,66 & 9,11 & 1,75 & 1,10 & $59,06 \%$ & 322,02 & 4,11 & 4,53 & $-9,27 \%$ \\
\hline
\end{tabular}


Table 12: Comparison of results of numerical analyses and laboratory tests for a model of a liner with a diameter of $500 \mathrm{~mm}$ and $14,00 \mathrm{~mm}$ wall thickness.

\begin{tabular}{|c|c|c|c|c|c|c|c|c|c|c|}
\hline \multirow[t]{4}{*}{ No. } & \multirow[t]{4}{*}{$\mathrm{h}[\mathrm{mm}]$} & \multirow{4}{*}{$\begin{array}{l}\mathrm{L} \\
{[\mathrm{mm}]}\end{array}$} & \multicolumn{4}{|c|}{ Stage of deformation $-0,05 \%$} & \multicolumn{4}{|c|}{ Stage of deformation $-0,25 \%$} \\
\hline & & & \multicolumn{8}{|c|}{ according to PN-EN ISO 178:2019-06 [9] } \\
\hline & & & \multirow{2}{*}{$\mathrm{F}_{1}[\mathrm{~N}]$} & Lab. tests & FEM & \multirow[t]{2}{*}{ difference } & \multirow[t]{2}{*}{$\mathrm{F}_{2}[\mathrm{~N}]$} & Lab. tests & FEM & \multirow[t]{2}{*}{ difference } \\
\hline & & & & \multicolumn{2}{|l|}{$\mathbf{s}_{1}[\mathrm{~mm}]$} & & & \multicolumn{2}{|c|}{$\mathrm{s}_{2}[\mathrm{~mm}]$} & \\
\hline 1 & 14,00 & 224,00 & 9,50 & 2,09 & 1,10 & $90,06 \%$ & 350,00 & 4,96 & 5,30 & $-6,46 \%$ \\
\hline 2 & 14,50 & 232,00 & 9,60 & 2,13 & 1,05 & $103,23 \%$ & 351,00 & 4,67 & 5,32 & $-12,11 \%$ \\
\hline 3 & 14,10 & 225,60 & 9,56 & 1,90 & 1,11 & $71,45 \%$ & 350,50 & 4,74 & 5,31 & $-10,60 \%$ \\
\hline 4 & 14,20 & 227,20 & 9,59 & 2,24 & 1,11 & $101,54 \%$ & 349,80 & 4,83 & 5,30 & $-8,83 \%$ \\
\hline 5 & 14,60 & 233,60 & 9,49 & 2,12 & 1,10 & $92,87 \%$ & 349,90 & 4,58 & 5,30 & $-13,52 \%$ \\
\hline 6 & 14,80 & 236,80 & 9,62 & 2,20 & 1,11 & $97,84 \%$ & 349,20 & 4,46 & 5,29 & $-15,58 \%$ \\
\hline Ave. & 14,37 & 229,86 & 9,56 & 2,11 & 1,10 & $92,75 \%$ & 350,07 & 4,71 & 5,30 & $-11,18 \%$ \\
\hline
\end{tabular}

\section{Conclusions}

\subsection{Analysis of the results obtained for the engineering calculations}

- The above comparisons of the obtained results (see Figs. 4, 5, and 6), presented in the form of diagrams, confirm for all the algorithms that there is a reduction of the load-bearing capacity with an increase in the diameter of a conduit.

- The parameter that allows the value of external loads to be increased is the wall thickness of the liner.

- The values obtained according to the ATV-DVWK calculations, regardless of the diameter and thickness of the liner, remain the smallest and thus guarantee high values of safety factors.

- Most diagrams for DN200 have an exponential shape. Only the values obtained using the ASTM algorithm give a linear course. This tendency changes with an increase in diameter. For DN500, the exponential course of most of the graphs changes into linear, and the graph for the values obtained using the ASTM algorithm changes its form to exponential.

- It should be concluded that the value of the bend radius of the lining has a direct impact on the curve of the $\mathrm{p}_{\mathrm{cr}}$ value.

- The lowest values of the permissible external critical pressure were obtained using the DWA algorithm, which confirms the safety of the structure with regard to its operation and load-bearing capacity.

\subsection{Analysis of the results obtained for the FEM method}

- When comparing the course of the laboratory tests with numerical analyses carried out with the use of FEM, with regard to the obtained deflection values (the relationship deflection-load), significant discrepancies in the initial stages of loading the samples are noticeable. This is a result of the abovedescribed heterogeneity of individual fragments of the CIPP liner samples.

- With an increase in load, the differences in deflections decrease - which is confirmed by all the conducted tests and the corresponding numerical analyses.

- The tendency, which shows that there is a convergence with an increase in load, allows for the conclusion, with regard to the obtained results that the numerical models have the correct parameterisation.

- The discrepancy in the deflection values (resulting from the imperfections in the liner samples) in the initial stage of the load increment prevents the use of the numerical model as a tool to replace acceptance laboratory tests - in particular the three-point bending test. This is due to the inconvenience that results from the need to precisely model all the irregularities to which a sample of a liner taken from the place of its installation is exposed.

- The numerical model can be successfully applied to determine the maximum permissible values of loads acting on the tested liner during the process of its design. 


\section{Summary}

The engineering calculations, computer simulations, and tests of felt liners hardened with epoxy resins, which were performed as part of the research programme, enabled knowledge in the field of designing, as well as the subsequent safe operation of conduits reinforced with a CIPP liner, to be extended. Laboratory tests, which are the basic source of knowledge about the actual strength parameters of the liner, were verified with available alternative calculation techniques.

Control simulations were made using the Abaqus program and the FEM. The liner samples were modelled and loaded in the same way as in the previous laboratory tests. The obtained results showed that the samples taken from the place of liner installation, due to their irregularities (such as variable thickness and geometric irregularities), obtained different values at the initial stage of the test than the corresponding numerical models, which did not include local geometric defects. In extreme cases, the values obtained in the initial phase of the study differed by over $100 \%$. As the load increased, there was "adjustment" of the sample, and the obtained values of deflections for a given force were closer to the values from the laboratory tests. In the next phase of the loading, the differences oscillated at around $10 \%$.

Analyses concerning the comparison of the deflection values obtained in the course of laboratory tests, and the deflection values obtained for the subsequent stages of the simulations on the numerical models showed that:

- due to the inhomogeneity of the samples, which results in disturbances of the obtained values, it is not possible during the initial phase of the test to replace the acceptance tests with analyses carried out on the numerical model,

- in the case of testing the basic strength parameters of CIPP liners, it is not necessary to destroy the sample. Consistent results of laboratory tests and numerical analyses are even obtained for the value of $25 \%$ of the maximum deflection,

- it is possible to use the numerical model in the design phase in order to determine the initial strength parameters, i.e. ring stiffness or bending strength.

In addition, the analysis of the conducted engineering calculations showed that two calculation methods, which are the prototype for the others, i.e. the Glock algorithm and the Tiimoshenka algorithm, give the highestvalue results. This is due to a general approach to the influence of imperfections that may affect the liner that is installed inside the conduit. All other algorithms take into account geometric irregularities individually (each group separately) to a smaller or larger extent, which results in the obtaining of lower strength parameters of the CIPP liner. The algorithm that takes into account the imperfections to the greatest extent is the DWA algorithm. In this case, the obtained values are the lowest, which translates into a high value of the safety factor and also guarantees the acceptable value of critical pressure $\mathrm{p}_{\mathrm{cr}}$ at a level that does not endanger the safety of the composite structure (pipe-lining). This, in relation to the difficult and complex operating conditions of the objects in question, guarantees many years of failurefree operation of a sewage network renovated with the use of CIPP lining.

The conducted research works, including the laboratory tests, engineering calculations, and computer simulations, allowed design and operational parameters that are required in the case of repairs of damaged conduits to be verified. A control study with the use of various tools gives knowledge about the actual permissible values (in particular, critical pressure) and irregularities that are inevitable and that occur in the case of liner samples and which, therefore, must be taken into account at the design stage of sewer renovations.

\section{References}

[1] Thepot O., International Comparison of Methods for the Design of Sewer Linings, 3R International 8-9, Vulcan-Verlag GmbH, Essen, 2004

[2] Falter B.: Structural design of linings, Proceedings of the International Conference on Underground Infrastructure Research, Kitchener, Ontario, Balkema publisher, 2001, s. 49-58

[3] ASTM F 1216, Standard practice for rehabilitation of existing pipelines and conduits by the inversion and curing of a resin impregnated tube, ASTM Designation, Philadelphia, 1998.

[4] RERAU. Project national Réhabilitation des réseaux d?assainissement urbains. Reconstructuration des collecteurs visitables, Guide technique Tome 1, 2002.

[5] WRc/WAA 4th ed. Sewerage Rehabilitation Manual (SRM), UK Water Research Centre/Water Authorities Association, Swindon, 2001.

[6] DWA-A 143-2: Sanierung von Entwässerungssystemen außerhalb von Gebäuden Teil 2: Statische Berechnung zur Sanierung von Abwasserleitungen und -kanälen mit Lining und Montageverfahren, Lipiec 2015

[7] Abel T., Laboratory tests and analysis of CIPP epoxy-resin internal liners used in pipelines - part I: comparison of tests and engineering calculations, Studia Geotechnica et Mechanica, accepted for publication on 31.01.2021

[8] Rusiński E.: The Finite Element Method, Wydawnictwo Komunikacji i Łączności. Warsaw, 1994. 
[9] PN-EN ISO 178:2019-06 - Plastics - Determination of flexural properties

[10] GWT manual, 2000. Germann Instruments, Denmark.

[11] Timoshenko S.P., Gere J.M.: Theory of Elastic Stability. Mc Graw - Hill. New York, 1961.

[12] Glock D.: Überkritisches Verhalten eines starr ummantelten Kreisrohres bei Wasserdruck von außen und Temperaturerhöhung, Der Stahlbau 46, 1977, s. 212-217.

[13] Madryas C., Szot A., Structural sensitivity of circular sewer liners to geometrical imperfections, Tunnelling and Underground Space Technology 18 (2003) 421-434, Elsevier Science Ltd. 2003

[14] Law T.C.M., Moore I. D., Numerical modeling of tight fitting flexible liner in damaged sewer under earth loads, Tunnelling and Underground Space Technology 22 (2007) 655-665, Elsevier Science Ltd. 2007

[15] Abel. T., Changes in strength parameters of pipelines rehabilitated with close-fit Trolining liners - Numerical analysis based on laboratory tests, Archives of Civil and Mechanical Engineering 16 (2016) 30 - 40, Wroctaw, 2015

[16] Zhao W. Z., Hall D., 3D Modeling of pipe liners with thickness variations, International No-Dig Show 2004, New Orleans, 2004

[17] Jaganathan A., Allouche E., Baumert M., Experimental and numerical evaluation of the impact of folds on the pressure rating of CIPP liners, Tunnelling and Underground Space Technology 22 (2007) 666-678, Elsevier Science Ltd. 2007

[18] Khademi-Zahedi R., Shishesaz M., Application of a finite element method to stress distribution in buried patch repaired polyethylene gas pipes, Underground Space 4 (2019) 48-58, Elsevier Science Ltd. 2019

[19] Shou K.J., Chen B.C., Numerical analysis of the mechanical behaviors of pressurized underground pipelines rehabilitated by cured-in-place-pipe method, Tunnelling and Underground Space Technology 71 (2018) 544-554, Elsevier Science Ltd. 2018

[20] Shou K.J., Huang C.C., Numerical analysis of straight and curved underground pipeline performance after rehabilitation by cured-in-place method, Underground Space 5 (2020) 30-42, Elsevier B.V., 2020

[21] Arumugam T., Karuppanan S., Ovinis M., Finite element analyses of corroded pipeline with single defect subjected to internal pressure and axial compressive stress, Marine Structures 72 (2020) 102746, Elsevier Science Ltd. 2020

[22] Boot J.C., Elastic buckling of cylindrical pipe linings with small imperfections subject to external pressure, Trenchless Technology Research, VOL. 12, No. 1-2, pp. 3-15, Elsevier Science Ltd. 1998, England

[23] Thépot O.: A new design method for non a circular sewer linings. Trenchless Technology Research 15, 2000, s. 25-41.

[24] Abaqus - Wroctaw Center for Networking and Supercomputing (http://www.wcss.pl) 